\title{
Identidade e subjetividade numa era de incerteza
}

\author{
Ariane Patrícia Ewald \\ Jorge Coelho Soares \\ Universidade do Estado do Rio de Janeiro
}

\begin{abstract}
Resumo
Este artigo se propõe a percorrer, seguindo uma trilha de reflexão transdisciplinar, os caminhos de construção do que conhecemos como a noção de pessoa, sob a qual subentendemos a existência de conceitos como subjetividade e identidade. Os autores procuram romper as fronteiras tradicionais entre os diversos saberes, que tentam dar conta do homem e seus novos dilemas, no contexto histórico da modernidade tardia, aqui tratada como hipermodernidade. Nesta sociedade que se vê, se constrói e se apresenta como globalizada, os autores colocam seu foco nas artimanhas da construção das novas identidades em contextos multiculturais, nos quais novas possibilidades de ser e estar no mundo convivem com novas formas de tensão e resistência social.

Palavras-chave: identidade; subjetividade; cultura; hipermodernidade
\end{abstract}

\begin{abstract}
Identity and subjectivity in uncertainty age. The purpose of this article is to pursue the path of construction of what we know as the notion of person, which we relate to the existence of concepts such as subjectivity and identity. This path entails a trail of transdisciplinary reflection, in which the authors seek to break traditional barriers in several areas of knowledge, try to deal with men and their modern conundrums in the historic context of the late modernity, here treated as hypermodernity. In this society which is seen, built and introduced as globalized, the authors put the focus on the means of the construction of new identities in multicultural contexts, in which new possibilities of being in the world coexist with new forms of social tension and resistance.
\end{abstract}

Keywords: identity; subjectivity; culture; hypermodernity

O homem, este ser flexível, que se submete na sociedade aos pensamentos e às impressões dos outros homens, é capaz tanto de conhecer sua própria natureza quando ela é mostrada a ele quanto perdê-la quando não imagina que ela lhe está sendo roubada.

Montesquieu, O Espírito das Leis.

$\mathrm{G}$ ostaríamos de iniciar este texto com o que Ralph Linton, antropólogo e professor de antropologia, escreveu na introdução do seu livro $O$ homem: uma introdução à Antropologia (The study of man: an introduction), originalmente publicado em 1936. Diz ele:

Este livro foi escrito numa época de confusão e de incerteza. Ainda é cedo para dizer se o Mundo Ocidental se restabelecerá das feridas que a si mesmo inflingiu na Guerra Mundial, ou se um restabelecimento incompleto será apenas, como parece mais provável, indício de uma segunda e presumivelmente mais eficiente tentativa de suicídio. Já houve uma Idade de Trevas e não há razão para que ela não se repita. (1970, p. 17)

Suas palavras pareciam proféticas, pois, poucos anos depois, estávamos novamente mergulhados num período de trevas: a segunda Guerra Mundial. Acreditávamos, talvez, que a Grande Guerra, a primeira, seria necessária para acabar com todas as guerras. Mas parece que, cada vez mais, temos mergulhado numa era de incertezas em que o ser humano tem se tornado apenas um alvo a ser exterminado, através de distâncias cada vez "seguras". Extermínio que parte sempre da premissa de que "alguns são mais humanos do que outros" e de que o outro é a priori sempre suspeito na sua imprevisibilidade. A suspeição cai também sobre a alteridade, pois nos remete aos domínios do desconhecido, nos afastando do mundo consabido de nossa cultura. Onze de setembro mostrou a todos nós o quão perigoso é sustentar este olhar enviesado sobre o outro. Desde então, as comunidades acadêmicas, espal hadas por todo o mundo, têm se preocupado em colocar em discussão uma questão que, há algum tempo, vinha sendo discutida de maneira velada e que com os acontecimentos daquele mês de setembro, se tornaram o foco principal da mídia e invadiram o cotidiano de milhões de pessoas: o tema da diferença. Parece que nunca havíamos nos empenhado tanto em discutir porque somos o que somos ou como viemos a nos tornar tal pessoa.

Não é uma novidade para a Psicologia, a Sociologia e a Antropologia refletir sobre o processo de formação da pessoa, 
seu desenvolvimento enquanto sujeito histórico e social. "A preocupação com a identidade", afirma Boaventura de Sousa Santos (1994), "não é, obviamente, nova. Podemos dizer até que a modernidade nasce dela e com ela" (p. 120). Mas, nesse momento, as discussões têm tomado rumos bastante diferentes, pois levam em consideração todas as transformações, inclusive tecnológicas, pelas quais passamos nos últimos tempos. Pode-se dizer, com certeza, junto com o sociólogo alemão Norbert Elias (1994), a partir do seu livro O processo civilizador, que o homem é uma lenta e prolongada construção do próprio homem. "Viver na incerteza é traumático", disse Agnes Heller (1999). "Viver na incerteza de significados e de valores é ainda mais", completa ela (1999, p. 21). Não podemos então escapar, nos alertou ainda esta mesma autora, pela omissão sistemática do pensar e refletir sobre a nossa condição primeira, como intelectuais e cidadãos. Essa condição que nos remete a buscar uma resposta às seguintes perguntas: "como se deve pensar, como se deve agir, como se deve viver?" (Heller, 1983, p. 11).

Talvez, nesse início de novo século e milênio, não tenhamos conseguido prever que, num mundo como o que estamos vivendo, interligado por conexões virtuais comunicativas em velocidade surpreendente e onde o tempo de trabalho diário parece ter abandonado a lógica do amanhecer e do entardecer, que as diferenças entre nós seriam também tão fartamente acentuadas. O processo de homogeneização cultural que tem ocorrido como desdobramento da globalização, parece ter, ao mesmo tempo, acentuado ainda mais certas diferenças, desigualdades, misérias e injustiças de todo gênero.

É necessário, portanto, refletir sobre este processo de construção do ser humano, sobre a relação entre indivíduo e sociedade, entre identidade e cultura (Ewald, 1997), temas que nos empurram para uma discussão em que estamos existencialmente inseridos. Para isso, partimos de contribuições de autores das várias áreas pertencentes às Ciências Humanas e Sociais que, acreditamos, nos fornecem subsídios preciosos à reflexão sobre essas questões.

Quando em, aproximadamente, 1560 o jovem e futuro filósofo Michel de Montaigne (1533-1592) tentava a vida como cortesão na corte de Carlos IX, teve a oportunidade de presenciar uma verdadeira "instalação" indígena proveniente do novo mundo nas terras francesas na cidade de Rouen. Anos mais tarde, nos seus Ensaios, descreveria essa experiência, colocando em questão a noção de diferença, aparentemente repousada no primado da civilização, à qual pertencia, e os outros, os "canibais", mas sem prender-se, contudo, à idéia de barbárie como designação dessa diferença e, ao mesmo tempo, nos fornecendo talvez uma primeira reflexão escrita sobre a idéia de etnocentrismo. Diz ele:

não vejo nada de bárbaro ou selvagem no que dizem daqueles povos; (...) na verdade, cada qual considera bárbaro o que não se pratica em sua terra. Julgamos [os outros, continua ele] pela idéia dos usos e costumes do país em que vivemos. Neste, a religião é sempre a melhor, a administração excelente, e tudo o mais perfeito. (Montaigne, 1987, p. 101)

Ao finalizar seu texto sobre "os canibais", ele divertidamente reconhece que só uma coisa o espantou acerca dos índios: “Tudo isso, em verdade, é muito interessante, mas, que diabo, essa gente não usa calças!" (1987, p. 101). A diferença está presente o tempo inteiro, acentua esta frase, mas parece que temos feito dela um jogo de interesses políticos e de busca de benefícios, cada qual para sua própria minoria, com a justificativa de que se é mais minoria que as outras minorias e assim sucessivamente.

O que é, portanto, isso que chamamos de identidade? Que nos faz igual e diferente de um e de muitos?

$\mathrm{O}$ termo identidade vem designando, primeiramente, o caráter do que é idêntico. Pode-se pensar a identidade a partir, por exemplo, da matemática ou da natureza, onde a idéia de uma essência é compartilhada, como já era visível nas definições do século XIX (Grand Dictionnaire Universelle du XIXe Siècle, 1873, p. 548). Mas, ao usarmos o termo em relação à existência subjetiva, ele ganha em sentido de permanência e de continuidade e o termo identidade cultural acentua a dimensão intersubjetiva, formal e concreta, da identidade pessoal (Clain, 1990, p. 1211). Dessa forma, é possível perceber a relação entre identidade pessoal e cultural, já que a cultura pode ser pensada como uma unidade expressiva que orienta a ação de uma comunidade. Fenomenologicamente falando, diríamos um horizonte de significação e valores. Se para pensar a identidade é necessário partir de uma essência compartilhada, semelhante, comum - do latim communis, que pertence a muitos ou a todos -, o sentido de identidade pessoal pode ser resumido ao que "permanece sempre na vizinhança de si mesmo", como nos indicou o Grand Dictionnaire Universelle du XIXe Siècle (1873, pp. 548-549, grifo nosso). Em outras palavras, na formação da sua singularidade, o si mesmo, cada um compartilha valores e crenças da sua comunidade, não se afasta do seu tempo, do seu sexo, da sua condição. A identidade pessoal, portanto, que nos faz sentir tão próximos de nós mesmos - "igualdade reflexiva a si mesmo" (Clain, 1990, p. 1211), indica que somos também relativos ao mundo em que vivemos ${ }^{1}$. A identidade pessoal, afirma Martin Baró (1989, citado por Gonzáles-Rey, 2003), é, ao mesmo tempo, "produto da sociedade e produto da ação do próprio indivíduo. [...] se forma na confluência de uma série de forças sociais que operam sobre o indivíduo e diante das quais o indivíduo atua e se faz a si mesmo" (p. 201). Portanto, ao nos referirmos à identidade, falamos de zonas de interseções, de vários tipos e tamanhos, pois são zonas de compartilhamento intersubjetivo com um grupo, um time de futebol, um bairro, uma cidade, um estado, um país, uma opção ideológico-polítca, etc., mas onde, também, sempre haverá o espaço da singularidade.

Para Boaventura de Sousa Santos (1994), "o primeiro nome moderno da identidade é a subjetividade" (p. 120). A palavra foi formada a partir do termo subjetivo, designando aquilo que pertence à consciência individual, como também o pertencente ao pensamento humano (Faye, 1990, p. 2477). Mas subjetividade diz respeito à constituição, isto é, ao fundamento, aquilo que viabiliza essas identidades, mas que fica subjacente. Retomase, necessariamente, o sentido da palavra grega traduzida para o latim como subiectum, "a noção do que é fundamental e que permanece 'subjacente"". Pode-se dizer, dessa forma, que a subjetividade corresponde à existência de uma essência "sub-jacente" à experiência, pois designa a consciência de si (Faye,1990, p. 2477) que, no dizer de Merleau-Ponty (1962, 
p. 230), concilia no homem os dois extremos: a consciência individual e o pensamento geral na síntese da consciência de si. Assim, subjetividade pode ser definida como o fundamento da identidade, social e individual, o que nos remete também à questão da alteridade.

A pesquisa antropológica trata, no tempo presente, da questão do outro, afirma o antropólogo Marc Augé (1994), uma "alteridade essencial ou íntima" (p. 22). As representações dessa alteridade, para ele, se situam no próprio cerne da individualidade que não pode ser dissociada da identidade coletiva e da identidade individual. Como já apontamos anteriormente por meio de outros autores, Marc Augé também reforça esse liame entre o social e o individual. Para ele, "toda representação do indivíduo é, necessariamente, uma representação do vínculo social que lhe é consubstancial. Por isso mesmo, somos devedores da antropologia das sociedades distantes, e mais ainda daqueles que ela estudou, por esta descoberta: o social começa no indivíduo" (1994, p. 24). O outro é, fundamentalmente, parte de mim mesmo, já nos indicava Sartre (1997), em 1943. Nossa subjetividade é, portanto, atravessada pela alteridade.

Pode-se conciliar a estas reflexões, em torno do conceito de subjetividade, a forma pela qual Castoriadis (1999) concebe, de forma bastante coesa, as noções de sujeito e subjetividade. Segundo ele,

O sujeito é essencialmente aquele que faz perguntas e que se questiona, seja no plano teórico ou no que chamamos prático. Chamarei subjetividade a capacidade de receber o sentido, de fazer algo com ele e de produzir sentido, dar sentido, fazer com que cada vez seja um sentido novo. (1999, p. 35).

Vê-se, nesse texto, que para esse autor-com possível aproximação do pensamento sartriano (Sartre, 1997) -, a questão do sujeito é a questão do projeto, é também a questão da psique e a questão do sentido. Ela se caracteriza pela reflexividade, que é a nossa capacidade de receber sentido, questionar o sentido e criar um novo sentido, pois esta subjetividade possui a capacidade do trabalho lúcido sobre si, da atividade deliberadora - a vontade. É saber que sabemos, e interrogar-se sobre tal saber, é colocar a si mesmo como objeto por posição e não por natureza (Castoriadis, 1999, p. 35). A verdadeira vontade, afirma ainda ele,

Não se refere à escolha de duas possibilidades pré-determinadas, mas a esse ato único, incoativo [que dá início], no e pelo qual surgem novos possíveis e, ao mesmo tempo, o sujeito se dirige para eles. Tal sujeito não é uma realidade, é um projeto, em parte realizado pelos indivíduos e em parte, sobretudo, a ser realizado também em função de uma transformação que se refere não apenas aos seres humanos na sua singularidade, mas à sociedade em seu conjunto. (1999, pp. 45-46)

Em artigo sobre a questão da diversidade cultural, debatido numa Convenção da Unesco, Emir Sader (2005) lembra que cultura não é mercadoria, muito menos a identidade cultural que caracteriza cada comunidade, pois ambos são portadores de valores e sentidos. Segundo ele, há uma tentativa de hegemonia cultural estadunidense no mundo de hoje e a "globalização liberal" tornou-se eficiente em divulgar tal visão particular do mundo para todas as culturas. Por outro lado, afirma Pierucci (1999), o que sabemos é que a globalização em sua fase atual tem tido um impacto contestador efetivamente pluralizante sobre as antigas identidades sociais essencializadas, $[. .$.$] fazendo com$ que as eventuais identidades coletivas em fase de construção ou reprocessamento, [...] se tornem mais posicionais, mais políticas, mais plurais e mais diversas; menos fixas, menos definitivas, menos unificadas, cada vez menos trans-históricas e cada vez mais transculturais. (p. 176)

As identidades grupais, deste ponto de vista apontado por Pierucci, funcionam cada vez menos na órbita do idêntico, do mesmo, da permanência; se mostram cada vez menos fixas e essenciais e cada vez mais posicionais, mais flexíveis, nômades, múltiplas, híbridas, proliferantes (1999, p. 176). As identidades hipermodernas podem, então, ser caracterizadas por aquilo que Marc Augé chamou de não-lugares, pontos de identificação coletiva que se tornaram, mais do que nunca, extremamente flutuantes. Esses não-lugares estão disponíveis em todos os países e cidades e criou-se, com isso, uma sensação de unidade do espaço terrestre, mas que, ao mesmo tempo, amplia o "clamor dos particularismos" (1994, pp. 36-37), afirma ele, em consonância com o pensamento de Pierucci (1999). É uma sociedade paradoxal, como também já caracterizou Lipovetsky (2006), sociedade do excesso, da urgência; sociedade que enfatiza o desejo afirmando a "liberdade" de informação e de consumo, ao mesmo tempo, lança a todos nós no jogo do mercado, da ordem comercial. O hiperconsumidor, no dizer de Lipovetsky, não é simplesmente ávido por um bem-estar material, mas ele aparece como um solicitante exponencial do conforto psíquico, de harmonia interior, cujas técnicas do desenvolvimento pessoal são disso fundamentais testemunhas: a expansão de um mercado da $\operatorname{alma}(2006$, p. 13).

Por um lado a sociedade do hiperconsumo exalta os referenciais do ser-melhor, da harmonia e do equilíbrio; de outro ela se dá como um sistema hipertrófico e incontrolado, uma ordem bulímica que conduz ao extremo e ao caos e que neles deve co-habitar a opulência com a amplificação das desigualdades e do subconsumo. (Lipovetsky, 2006, p. 16)

Esse sentido paradoxal, talvez acentuado pelo processo de globalização, tornou as fronteiras do mundo tão permeáveis e possibilitou também identidades tão voltadas para si, ao mesmo tempo, outras identidades tão descentradas, deslocadas ou fragmentadas (Giddens, 1991; Hall, 2001). Perdemos pelas margens da nossa própria história, a construção das identidades sólidas que nos apareciam como um "porto seguro", no qual nossa existência subjetiva se apoiava. É exatamente nesse ponto que, na emergência dos interstícios - a sobreposição e o deslocamento de domínios da diferença - que, segundo Homi K. Bhabha (1998), "as experiências intersubjetivas e coletivas de nação [nationness], o interesse comunitário ou o valor cultural são negociados" (p. 20). Temos de pensar a história da nossa construção enquanto comunidade humana; nos voltarmos para as concepções de ser humano cujos desdobramentos encontramos na nossa contemporaneidade.

Nesse sentido, uma das concepções fundamentais de ser humano, cuja marca ainda está presente na nossa contempora- 
neidade, emana do Iluminismo, cuja crença irrestrita na razão buscava dar conta do mundo e dos fenômenos que nos cercam. Essa concepção apresentava o sujeito como dotado de uma "razão que tudo sabe", cujo centro era um núcleo interior que acabava por se constituir como a sua identidade. É o momento da "experiência da subjetividade privatizada", afirma Luís Cláudio Figueiredo (1991), ao analisar as pré-condições para a formulação de projetos de psicologia científica, e que nos dá a idéia de "sermos sujeitos capazes de decisões, sentimentos e emoções privadas” (p. 17). Essa concepção só faz sentido numa sociedade em que aparece uma oposição entre natureza e ser humano: enquanto a primeira segue os princípios da necessidade causal, o ser humano é dotado de liberdade e razão, agindo por escolha de acordo com valores e fins. As características centrais da "filosofia moral da Ilustração" - o cognitivismo, o individualismo e o universalismo - apontadas por Sérgio Paulo Rouanet (1992), mapeiam com clareza esse novo cenário conceitual sobre o ser humano e suas relações.

No seu texto "Resposta à pergunta: Que é "Esclarecimento"?”, de 1783, Kant aponta de imediato sua crença na razão e na possibilidade de mudança. Para ele, o Esclarecimento "é a saída do homem de sua menoridade, da qual ele próprio é culpado. A menoridade é a incapacidade de fazer uso de seu entendimento sem a direção de outro indivíduo. (...) É tão cômodo ser menor"(Kant, [1783] 1985, p. 100, grifos do autor).

É nesse momento que a idéia de cultura adquire novo significado: num primeiro momento a palavra cultura, do latim colere - cultiva, cuidar, prosperar, significava, além do cuidado com a natureza, também o cuidado com a educação das crianças que deveriam se tornar membros virtuosos da sociedade, aperfeiçoando nelas as qualidades naturais (Virton, 1966, p. 360 e sgts.). Num outro momento, cultura passa a significar os resultados daquela educação. Esses resultados são as expressões de um povo em tudo o que realiza ${ }^{2}$. Como, a partir do século XVIII, os resultados daquela educação são alcançados através do esforço despendido em escolhas racionais assentada em valores, a cultura torna-se o "lugar" da transformação, seja das relações interpessoais, da relação com o tempo, o espaço e a própria natureza. Sinteticamente, poderíamos dizer que "a cultura compreende a soma e estruturação de todo o saber, o 'saber agir' e o 'saber viver' do conjunto dos homens que vivem nessa sociedade" (Emile Pin, apud Virton, 1966, p. 363).

Essas noções levam alguns autores a repensar o ser humano de maneira menos individualista, menos "centrada". É o que faz George Herbert Mead, que expõe uma concepção sobre o sujeito a partir da ação. Sua idéia, exposta no seu já clássico trabalho Espiritu, Persona y Sociedad (1953), é a de que o ser humano é formado na relação com os outros e sua ação determina a relação entre a pessoa e o ambiente (Deutsch \& Krauss, 1974, p. 174). Ao analisar a pessoa, Mead avisa que ela não está presente no nascimento, pois é algo que contém em si desenvolvimento, isto é, a pessoa, afirma ele, "surge no processo da experiência e das atividades sociais". Em outras palavras, "o ser humano se desenvolve como resultado de suas relações com esse processo como um todo e com os outros indivíduos que se encontram dentro desse processo" (Mead, 1953, p. 167). Seu ponto fundamental é o de que o ser humano, como pessoa autoconsciente, só é pos- sível assentado sobre a sociedade à qual pertence (p. 186), ou, dizendo de outra maneira, sobre um sentido de pertencimento a uma comunidade.

A então nascente Antropologia Cultural pretendia "não só descrever, mas compreender os fenômenos culturais característicos de uma sociedade". Para tanto, buscava uma correlação entre indivíduo e sociedade, mais especificamente, entre indivíduo e cultura, apresentando os fenômenos culturais "na sua relação vivida com os comportamentos coletivos ou individuais" (Duchac, 1975, p. 21, ambas as citações). O que surge daí é uma concepção dialética e recíproca entre cultura e indivíduo, cuja imagem poderia corresponder a um tecido em que ambas as fontes se tornam os fios que formam a trama, fornecendo coerência interna e externa. A isso passamos a chamar nós-mesmos.

A questão que estamos discutindo aqui, portanto, versa sobre a construção social do ser humano, objeto de preocupação central nos estudos de psicologia. Seria oportuno chamar a atenção para uma coletânea de textos sobre um tema que acabou por se tornar, para os franceses, uma de suas maiores preocupações sociais: as tensões de uma anunciada diversidade cultural, agudizada nos últimos anos, em decorrência da imigração, justificada por inúmeros fatores entre os quais uma crescente necessidade de mão-de-obra não especializada, que terminou por fermentar o crescimento das bidonvilles multiculturais ${ }^{3}$. Os organizadores, Jean-Léon Beauvois, Willem Doise e Nicole Dubois (1999), reuniram no livro La construction sociale de la personne, uma discussão ampla, mas nem por isso menos profunda, dos principais temas da atualidade que instigam os pesquisadores em psicologia social: multiculturalismo, identidade social, identidade pessoal, valores e internalização de valores, socialização e internalização de comportamentos, submissão consentida, entre outros. O que se vê com clareza nesse estudo é que, mesmo em tempos de globalização e de fronteiras culturais permeáveis - e não de "fim de fronteiras" -, como reforça Ortiz (2006, p. 50), quando podemos facilmente deslocar os indivíduos cujas raízes não são fortes ou suficientemente profundas, o ser humano possui História, está imerso na sociedade, cercado de valores e interioriza dialeticamente o que lhe é dado por uma ou muitas culturas.

Sabemos que a ação significativa de outros grupos e/ou comunidades atua em qualquer sociedade como marco de referência para os mais variados tipos de pessoas. Compartilhando de modelos globalizados, disseminados pelas mais variadas formas de comunicação, tornamos acessíveis os mais variados tipos de identidades que deixam de estar vinculados a um lugar e a um tempo definidos. O uso de uma maneira de agir socialmente já não precisa, necessariamente, estar ligado a um povo; as identidades que outrora funcionavam como marcos totais, se fragmentam em vários pedaços que circulam pelo mundo e são apropriados em pequenas peças, sem contexto, sem lugar, sem tempo, sem história. Um produto que circula pelo mundo globalizado, cuja gênese vai lentamente se perdendo. Como afirma Stuart Hall (2001), as identidades "flutuam livremente" e se pode verificar uma certa homogeneização cultural, sinalizando para um senso comum planetário. Mas como nos lembra Ortiz (2006):

o senso comum não duvida de si mesmo, ele se impõe como 
um saber sólido e mineralizado, conferindo-nos a ilusão de que tudo se adapta à sua visão conceitual. Mas é sua certeza que incomoda, pois limita a inquietação intelectual ao círculo da experiência imediata, naturaliza o conhecimento das coisas, como se entre as categorias de pensamento e o mundo existisse uma transparência, uma coincidência de intenções. $O$ senso comum é pouco reflexivo e acredita que a aparência da realidade é a sua própria verdade. (p. 45)

Esta visão homogeinizante e uniformizante do processo de globalização é, também para Boaventura de Sousa Santos (2002), pouco adequada para dar conta deste fenômeno, que não pode ser reduzido às suas dimensões econômicas. Para este autor, a globalização é

um vasto e intenso campo de conflitos entre grupos sociais, Estados e interesses hegemônicos, por um lado, e grupo sociais, Estados e interesses subalternos, por outro; e mesmo no interior do campo hegemônico há divisões mais ou menos significativas. No entanto, por sobre todas as suas divisões internas, o campo hegemônico atua na base de um consenso entre os seus mais influentes membros. É esse consenso que não só confere à globalização as suas características dominantes, como também legitima estas últimas como as únicas possíveis ou as únicas adequadas (2002, p. 27).

Definimos globalização como conjuntos de relações sociais que se traduzem na intensificação das interações transacionais, sejam elas práticas interestatais, práticas capitalistas globais ou práticas sociais e culturais transacionais. (2002, p. 85)

A produção de globalização implica, para ele, em produção de localização e pode ser dividida em quatro formas: localismo globalizado - quando um determinado fenômeno local se torna globalizado (e.g., fast-food estadunidense); o globalismo localizado - é o impacto local "produzido pelas práticas e imperativos transnacionais que decorrem dos localismos globalizados”. As outras duas formas estão ligadas à noção de resistência no interior das práticas sociais e culturas transnacionais e dizem respeito à "globalização da resistência aos localismos globalizados e aos globalismos localizados: o cosmopolitismo - são práticas e discursos de resistência que podem ser indicados através das suas atividades como redes de solidariedade transnacional, articulação entre organizações operárias de diferentes países, redes internacionais de assistência jurídica, etc.; o patrimônio comum da humanidade: diz respeito às lutas transnacionais pela proteção e desmercadorização dos recursos, que se caracterizam por lutas ambientais, biodiversidade, etc.

O que observamos depois do "11 de setembro", e que parece que sempre se acentua em "situações-limite", como a guerra, por exemplo, é que os envolvidos esquecem, momentaneamente, suas diferenças internas e se fecham em torno de uma identidade que os unifique. Os norte-americanos se tornam mais norte-americanos, os árabes mais árabes. As diferenças internas da comunidade se diluem e as externas se acentuam e passamos a olhar a vida, passada e futura, com os óculos do presente, designando a partir daí novas direções de comportamentos, atitudes, relacionamentos sociais e valores. Dessa forma, a idéia de identidade cultural pode ser pensada como uma forma de mediação entre a pessoa e a sociedade, pois a cultura é uma unidade expressiva que orienta a ação individual e é, sem sombra de dúvida, um horizonte de significações que passa a fazer parte da nossa construção enquanto pessoa.

Discutir globalização e, ao mesmo tempo, diferença, parece paradoxal. Mas, lembrando a discussão feita por Pierucci (1999), que fala em produtividade social da diferença (p. 154), houve um tempo em que debatíamos a questão perguntando se somos todos iguais ou somos todos diferentes. O que este autor demarca é que, nos últimos 40 anos, continuamos a nos perguntar sobre as diferenças, mas desta vez nos perguntamos se "queremos ser iguais ou se queremos ser diferentes" (p. 7), já que as diferenças de fato foram expostas. Sim, somos diferentes, temos deuses diferentes, estilos diferentes, gostos diferentes, gastronomia diferente. Somos portadores, portanto, de pertenças culturais diferentes, afirma ele. E exatamente imbuídos desta necessidade de demarcação da diferença, acabamos exigindo/querendo o direito à diferença, "o direito de sermos pessoal e coletivamente diferentes uns do outros" (p. 7). Passamos a viver a necessidade de demarcar a diferença provocando assim, novas diferenças coletivas e individuais gerando a possibilidade de um abismo cada vez maior nas relações sociais e de cordialidade. Se o projeto da modernidade nos empurrou para um ideal de cidadão autônomo, senhor de si - corpo e mente-, o desenraizamento cultural deste homem passou a ser um desdobramento natural neste processo. A mundialização, tratada como fenômeno cultural da globalização por Renato Ortiz (1994), é um fenômeno social total, afirma ele, "que permeia o conjunto das manifestações culturais Para existir, ele deve se localizar, enraizar-se nas práticas cotidianas dos homens, sem o que seria uma expressão abstrata das relações sociais" (p. 31). Desta forma, a idéia de desenraizamento cultural e a de demarcação da diferença, permeiam nossas práticas cotidianas e nossa construção identitária.

Ao vasculhar os autos das devassas das inconfidências, Carlos Guilherme Mota (s.d.), por exemplo, descreve o andamento do processo de conscientização que ocorria nos brasileiros na época dos movimentos de inconfidências que ocorreram no Brasil entre 1789 e 1801, dando a entender que os movimentos acontecidos aqui no Brasil não foram simplesmente reflexos das revoluções européias. A tomada de consciência à qual Mota se refere, retrata a permanente necessidade de enxergar quem somos nós para poder, a partir daí, transformar a situação na qual nos vemos lançados. Para ele, os autos das devassas das inconfidências mostram a tomada de consciência dos brasileiros em relação a alguns componentes básicos do Antigo Regime Europeu, ou seja, o colonialismo, o absolutismo e o mercantilismo. Tinha-se consciência, afirma ele e de acordo com os termos utilizados pelos inconfidentes nos autos em relação à Europa, "de que a Europa estava "chupando toda a [nossa] substância", "de que o Rei era "como qualquer de nós";; "de que "isso da Religião é peta [mentira]"”; e de que aos "estudantes que saíam do Reino (sistema) não devia se conceder regresso". Estar consciente destas questões era perceber um ponto de relação crucial entre o colonizador e o colonizado que Jean-Paul Sartre, em seu texto “Colonialisme et néo-colonialisme”, (Situations, V, 1964), enunciou da seguinte forma: para o colonizador não há colonizado bom ou ruim, há simplesmente colonizados (p. 270) ${ }^{4}$. Isto pro- 
piciou uma comparação entre o que éramos e o que deveríamos ser, estabelecendo uma pontuação imaginária entre o grau de progresso que alcançáramos e o que eles, europeus, já haviam alcançado. Segundo Roland Corbisier (1977),

apesar do clima e da repugnância que lhe inspiram os costumes dos colonizados, o colonizador projeta sua existência na colônia em um tempo sem fim, pois nem por hipótese admite que um dia o colonizado possa sacudir o jugo a que se acha submetido. (p. 9)

Colocando também em discussão as questões trazidas pela pós-colonialidade e as lembranças das relações "neocoloniais" nessa "nova" ordem mundial, Homi Bhabha (1998) mostra que este movimento do "novo" internacionalismo é um "processo de deslocamento e disjunção que não totaliza a experiência. Cada vez mais as culturas "nacionais" estão sendo produzidas a partir da perspectiva de minorias destituídas" (p. 25). Para ele, os países devem contar suas histórias a partir de narrativas produzidas pelo influxo de migrantes e refugiados do pós-guerra. Tais narrativas, constituídas a partir da exploração e o desenvolvimento de estratégias de resistência, mostra a formação de comunidades e países "de outro modo que não a modernidade", segundo sua expressão.

Tais culturas de contra-modernidade pós colonial podem ser contingentes à modernidade, descontínuas ou em desacordo com ela, resistentes a suas opressivas tecnologias assimilacionistas; porém, elas também põem em campo o hibridismo cultural de suas condições fronteiriças para "traduzir", e portanto reinscrever, o imaginário social tanto da metrópole como da modernidade. (p. 26)

Mas o processo de interiorização de idéias passa também por um elo afetivo, elo este que cria laços de união entre os indivíduos e nossa "comunidade de destino", - aquela que elegemos como sendo nosso lugar de pertencimento, e à qual estamos integrados e nos dedicamos. Desta forma, as ações que realizamos cotidianamente têm seu ponto de referência na visão de mundo do grupo de pertencimento, e os horizontes dessa visão são definidos por este mesmo grupo. À medida que uma idéia se dissemina pela sua eficiência e toma conta das consciências, pensar fora dela demanda muito esforço emocional, posicionamento crítico e a coragem de ter que nadar contra a corrente, solitariamente.

Passamos a acreditar na modernidade hipermodernizante e no mundo globalizado em que vivemos, e que os inventos, o avanço da tecnologia e seus desdobramentos na nossa vida cotidiana seriam suficientes para aplacar as diferenças de todas as ordens. Creio que nos enganamos, pois, como afirma o poeta e crítico Charles Baudelaire, o ser humano parece ter perdido "a noção das diferenças que caracterizam os fenômenos do mundo físico e do mundo moral" (1995, p. 775).

O campo das práticas sociais e culturais transnacionais consiste na construção democrática das regras de reconhecimento recíproco entre identidades e entre culturas distintas, afirma Boaventura de Sousa Santos (2002, p. 75). Mesmo que isto leve a identidades duais, identidades híbridas, interidentidade e transidentidade, todas, segundo este autor, "devem orientar-se pela seguinte pauta transidentitária e transcultural: temos o direito de ser iguais quando a diferença nos inferioriza e a ser diferentes quando a igualdade nos descaracteriza" (2002, p. 75).

Gostaríamos de finalizar lembrando que em Psicologia não faz sentido falar em desenvolvimento sem falar em contexto de desenvolvimento (Booth, 1976), isto é, que toda vida humana se desenrola num horizonte específico, diretamente relacionado a um tempo histórico, social, vital e significativo, a partir do qual concretizamos a tarefa de ser-nós-mesmos. Há um processo dialético em curso que é inequívoco na construção da identidade pessoal.

O curso do desenvolvimento da personalidade é determinado, em grande parte, pelo modo como um indivíduo é tratado em sua cultura e as expectativas dos agentes socializantes sobre papéis apropriados à idade. Estes fatores determinam a amplitude de seu comportamento, assim como o conjunto de experiências que configuram sua visão do mundo. (Booth, 1976, p. 71)

Nos tornamos seres humanos não simplesmente por nascermos com as características físicas humanas, mas porque somos amplamente dimensionados por uma cultura, por um horizonte significativo, por uma comunidade de destino. Nesse processo, nos tornamos também diferentes, com modos de ser diferentes, mediados por culturas que nos unem e separam mas que, incondicionalmente, estão fadadas a viverem juntas.

Para encerrar, fazemos nossas as palavras do antropólogo Cliford Geertz (1989):

A cultura fornece o vínculo entre o que os homens são intrinsecamente capazes de se tornar e o que eles realmente se tornam, um por um. Tornar-se humano é tornar-se individual, e nós nos tornamos individuais sob a direção dos padrões culturais, sistemas de significados criados historicamente em termos dos quais damos forma, ordem, objetivo e direção às nossas vidas. (...) O homem não pode ser definido nem apenas por suas habilidades inatas, como fazia o iluminismo, nem apenas por seu comportamento real, como o faz grande parte da ciência social contemporânea, mas sim pelo elo entre eles, pela forma em que o primeiro é transformado no segundo (...). Assim como a cultura nos modelou como espécie única - e sem dúvida ainda está modelando - assim também ela nos modela como indivíduos separados. É isso o que temos realmente em comum - nem um ser subcultural imutável, nem um consenso de cruzamento cultural estabelecido. (p. 64)

\section{Referências}

Augé, M. (1994). Não-lugares. Introdução a uma antropologia da supermodernidade. Campinas, SP: Papirus.

Baudelaire, C. (1995). Exposição Universal (1855). In Poesia e Prosa. Rio de Janeiro: Nova Aguilar.

Beauvois, J.-L., Doise, W., \& Dubois, N. (1999). La construction sociale de la personne. Saint-Martin-d'Hères (Isère): PUG.

Bhabha, H. K. (2001). O Local da Cultura. Belo Horizonte: Editora da UFMG. Booth, T. (1976). Psicologia do crescimento em sociedade. Rio de Janeiro: Zahar.

Castoriadis. C. (1999). Para si e subjetividade. In A. Pena-Vega \& E. P. do Nascimento (Orgs.), O pensar complexo. Edgar Morin e a crise da modernidade (pp. 35-46). Rio de Janeiro: Garamond. 
Clain, O. (1990). Identité (-culturelle). In Encyclopédie Philosophique Universelle. Les Notions Philosophiques (v. 1, pp. 1222-1222). Paris: Presses Universitaires de France.

Corbisier, R. (1977). Prefácio [1967]. In Albert Memmi, Retrato do colonizado precedido pelo retrato do colonizador. Rio de Janeiro: Paz e Terra.

Deutsch, M., \& Krauss, R. M. (1974). Teorías en psicología social. Buenos Aires: Paidós.

Duchac, R. (1975). Sociologia e Psicologia. Lisboa: Bertrand.

Elias, N. (1994). O Processo civilizador. Rio de Janeiro: Jorge Zahar.

Ewald, A. P. (1997). Indústria cultural e subjetividade. Sociedady Utopia. Revista de Ciencias Sociales (Madrid), 9, 45-53.

Fanon, F. (1968). Os condenados da Terra. Rio de Janeiro: Civilização Brasileira.

Faye, E. (1990). Subjectivité. In Encyclopédie Philosophique Universelle. Les Notions Philosophiques (v. 2, pp. 2477-2480). Paris: Presses Universitaires de France.

Figueiredo, L. C. M. (1991). Psicologia, uma introdução. São Paulo: EDUC.

Geertz, C. (1989). A interpretação das culturas. Rio de Janeiro: Livros Técnicos e Científicos.

Gonzáles-Rey, F. L. (2003). Sujeito e subjetividade: uma aproximação históricocultural. São Paulo: Pioneira Thomson Learning.

Grand Dictionnaire Universel du XIXe Siècle. (1873). Paris, Tomo 9.

Giddens, A. (1991). As conseqüencias da modernidade. São Paulo: UNESP.

Hall, S. (2001). A identidade cultural na pós-modernidade. Rio de Janeiro: DP \& A.

Heller, A. (1983). A filosofia radical. São Paulo: Brasiliense.

Heller, A. (1999). Uma crise global da civilização: os desafios futuros. In A crise dos paradigmas sociais e os desafios para o século XXI (pp. 13-32). Rio de Janeiro: Contraponto.

Kant, I. (1985). Resposta à pergunta: que é "esclarecimento"? [1783]. In Textos Seletos. Petrópolis: Vozes.

Linton, R. (1970). O Homem, uma introdução à antropologia. São Paulo: Martins.

Lipovetsky, G. (2006). Lê bonheur paradoxal. Essai sur la société d'hyperconsommation. Paris: Gallimard.

Mead, G. H. (1953). Espiritu, persona y sociedad. Buenos Aires: Paidós.

Memmi, A. (1977). Retrato do colonizado precedido pelo retrato do colonizador. Rio de Janeiro: Paz e Terra.

Merleau-Ponty, M. (1962). Em toda parte e em nenhuma. In Sinais. Lisboa: Ensaio; Minotauro.

Montaigne, M. de. (1987). Ensaios (Os Pensadores). São Paulo: Nova Cultural. Mota, C. G. (s.d.). Atitudes de inovação no Brasil, 1789-1801. Belo Horizonte: Livros Horizonte.

Ortiz, R. (1994). Mundialização e cultura. São Paulo: Brasiliense.

Ortiz, R. (2006). Mundialização: saberes e crenças. São Paulo: Brasiliense.

Pierucci, A. F. (1999). Ciladas da diferença. São Paulo: Ed. 34.

Rouanet, S. P. (1992). Dilemas da moral iluminista. In A. Novaes (Org.), Ética. São Paulo: Companhia das Letras.

Sader, E. (2005). Cultura: identidade ou mercadoria? Jornal do Brasil, 9 de outubro, p. A15.

Sartre, J.-P. (1964). Colonialisme et néo-colonialisme. In Situations, V. Paris: Gallimard.

Sartre, J.-P. (1968). Prefácio [1961]. In F. Fanon, Os condenados da Terra. Rio de Janeiro: Civilização Brasileira.

Sartre, J.-P. (1997). O ser e o nada: ensaio de ontologia fenomenológica. Petrópolis: Vozes.

Santos, B. de S. (1994). Pela mão de Alice: o social e o político na pós-modernidade. Porto: Afrontamento.

Santos, B. de S. (2002). Os processos da globalização. In B. de S. Santos (Org.), A globalização e as Ciências Sociais (pp. 25-102). São Paulo: Cortez.

Soares, J. C. (1998). Mal-estar na modernidade tardia globalizada. Revista Ciências Humanas (Rio de Janeiro, Universidade Gama Filho), 21(2), 13-25.

Soares, J. C. (2000). A crise da sociedade contemporânea e o sofrimento psíquico. Revista Ciências Humanas (Rio de Janeiro, Universidade Gama Filho), 23(1-2), 220-231.

Starobinski, J. (2001). A palavra "civilização". In As máscaras da civilização: ensaios. São Paulo: Companhia das Letras.

Virton, P. (1966). Os dinamismos sociais. Lisboa: Herder. 
Notas

${ }^{1}$ Tomaremos neste texto a noção de personalidade como sinônima de identidade pessoal, já que a compreendemos como uma configuração única assumida no decurso da história de uma pessoa em integração com seu meio. Ela é, portanto, aquilo que se concretiza a partir das ações que realizamos no mundo e em contínua interação com ele.

${ }^{2}$ Paul Virton (1966) indicava que o termo cultura havia se tornado sinônimo do termo civilização e que muitos autores preferiam não fazer uma diferenciação exata dos dois termos. Ver também as discussões sobre os termos empreendidas por Norbert Elias (1994), especialmente a Parte I do Volume 1; Starobinski (2001).

${ }^{3}$ O filme La Haine [O Ódio], de Mathieu Kassovitz (1995), explora e coloca em cena, de forma brilhante, este novo cenário social de convivencialidade e tensão extrema.

${ }^{4}$ Ver também Fanon (1968), Os Condenados da Terra, e Memmi (1977), Retrato do colonizado precedido pelo retrato do colonizador. Em uma nota um pouco extensa, retiro as palavras do prefaciador de um dos livros, em que expõe a relação de opressão gerada pelo sistema colonial: "Numa palavra, o Terceiro Mundo se descobre e se exprime por meio desta voz. Sabemos que ele não é homogêneo e que nele se encontram ainda povos subjugados, outros que adquiriram uma falsa independência, outros que se batem para conquistar a soberania, outros enfim que obtiveram a liberdade plena mas vivem sob a constante ameaça de uma agressão imperialista. Essas diferenças nasceram da história colonial, isto é, da opressão. Aqui a Metrópole contentou-se em pagar alguns feudatários; ali, dividindo para reinar, fabricou em bloco uma burguesia de colonizados; mais além matou dois coelhos de uma só cajadada: a colônia é ao mesmo tempo exploração e povoamento. Assim a Europa multiplicou as divisões, as oposições, forjou classes e por vezes racismos, tentou por todos os meios provocar e incrementar a estratificação das sociedades colonizadas. Fanon não dissimula nada: para lutar contra nós, a antiga colônia deve lutar contra ela mesma. Ou melhor, as duas formas de luta são uma só. No fogo do combate, todas as barreiras interiores devem derreter-se" (J.-P. Sartre, "Prefácio", 1968, p. 6).

${ }^{5}$ No sentido exposto por Soares nos seguintes artigos: "Mal-Estar na Modernidade Tardia Globalizada", 1998; e "A crise da sociedade contemporânea e o sofrimento psíquico", de 2000.

Ariane Patrícia Ewald, doutora em Comunicação e Cultura pela Universidade Federal do Rio de Janeiro, é professora adjunta no Programa de Pós-Graduação em Psicologia Social da Universidade do Estado do Rio de Janeiro. Endereço para correspondência: Instituto de Psicologia/UERJ; Rua São Francisco Xavier, 524 - bloco B, sala 10.019, $10^{\circ}$ andar (Maracanã); Rio de Janeiro, RJ; CEP: 20.550-013. E-mail: aewald@, terra.com.br

Jorge Coelho Soares, doutor em Comunicação e Cultura pela Universidade Federal do Rio de Janeiro, é professor adjunto no Programa de Pós-Graduação em Psicologia Social, da Universidade do Estado do Rio de Janeiro. E-mail: jorge.coelho.soares@terra.com.br 